\title{
PROJETO FOGO: UM EXPERIMENTO PARA AVALIAR EFEITOS DAS QUEIMADAS DE CANA-DE-AÇÜCAR NA BAIXA ATMOSFERA
}

\author{
E.V.A. Marinho \& V.W.J.H. Kirchholf
}

\begin{abstract}
O projeto fogo foí idealizado com o objetivo de estudar o efeito das queimadas da palha da cana-de-açúcar sobre os gases atmosféricos ozỏnio $\left(\mathrm{O}_{3}\right)$, monóxido de carbono $(\mathrm{CO})$ e dióxido de carbono $\left(\mathrm{CO}_{2}\right)$. Foram realizadas várias campanhas de campo na superfície e no ar, a bordo de um avião Bandeirante instrumentado, na regiâo canavieira do Estado de São Paulo. Efeitos muito expressivos foram observados nas concentraçốes de $\mathrm{CO}$ e $\mathrm{O}_{3}$. Na época chuvosa quando nāo há queimadas as concentraçōes até $6 \mathrm{~km}$ de altitude são menores que $30 \mathrm{ppbv}$ (partes por billhăo por volume), para o $\mathrm{O}_{3}$ e cerca de $100 \mathrm{ppbv}$ para o $\mathrm{CO}$. Na época de queimada de palha da cana (setembro) foram observadas concentraçōes de até $80 \mathrm{ppbv}$ a cerca de $1,5 \mathrm{~km}$ de altitude para o $O_{3}$, e 600 ppbv para o $\mathrm{CO}$. Deve-se notar que estas medidas foram feitas a vários quilômetros de distância das fontes poluidoras, para caracterizar o estado médio da atmosfera inferior em equilfrio. Estima-se que somente no Estado de Sāo Paulo as queimadas da cana injetam na atmosfera cerca de 350.000 toneladas de carbone na forma de CO.
\end{abstract}

PROJECT FIRE: AN EXPERIMENT TO EVALUATE TII: EFFECTS OF SUGAR CANE BURNINGS IN THE LOWER ATMOSPHERE Project Fire was designed to study the effects that sugar cane bumings have on the atmospheric gases ozone $\left(\mathrm{O}_{3}\right)$, carbon monoxide $(\mathrm{CO})$, and carbon dioxide $\left(\mathrm{CO}_{2}\right)$. Several field campaigns were conducted the surface and on board of an aircraft, an instrumented Bandeirante, which flew over the sugat cane region of São Paulo. Strong enhancements were observed both in $\mathrm{CO}$ and $\mathrm{O}_{3}$ concentrations. During the rainy season, when there are no burnings, the concentrations up to $6 \mathrm{~km}$ of altitude are less then 30 ppbv (parts per bilion by volume), for $\mathrm{O}_{3}$ and about 100 pptiv for $\mathrm{CO}$. During the sugar cane burning period (September), we have observed concentrations up to $80 \mathrm{ppbv}$ at about 1.5 $\mathrm{km}$ of altitude for $\mathrm{O}_{3}$ and $600 \mathrm{ppbv}$ for $\mathrm{CO}$. It must be emphasized that such measurements were made several kilometers away from the pollution sources, characterizing in this way the mean state of the lower atmosphere in equilibrium. We estimate that only in the Sâo Paulo region the sugar cane burnings inject into the atmosphere about 350,000 tons of carbon in the form of $\mathrm{CO}$.

\section{INTRODUÇÃO}

A produçấo de açúcar foi por muito tempo uma atividade que preponderava no Nordeste. Recentemente houve o deslocamento paulatino da produção na direção C'entro-Sul. Assim, tornou-se o Brasil talvez o único país grande produtor no mundo, que realiza duas colheitas por ano: tuma no Norte-Nordeste, de dezembro a maio, e outra na região Centro-Sul de julho a dezembro. Devido at esta característica e visando criar $a$ independència do mercado nacional no que concerne aos combustíveis de automoveis, foi criado o Proál- cool, Programa Nacional de Álcool (Decreto 76593. de $14 / 11 / 1975)$.

O Brasil é hoje o maior produtor mundial de cana-de-açúcar e álcool. Até 1975 eram produzidós no país cerca de 500 millôes de litros por ano, utilizados na fabricaçâo de bebidas e açúcar além da indústria farmacêutica, Com a instituição do Proálcool, o álcool começou a ser adicionado à gasolina dos automoveis a partir de 1976 e em 1979 foram fabricados os primeiros vé́culos movidos a álcool. Este fato elevou a produção deste combustível a 12 bilhôes de litros anuais. A área de cana-de-açúcar colhida em todo o Brasil no 
ano de 1989 foi de 4,1 bilhóes de hectares, sendo que o Estado de São Paulo sozinho contribuiu com mais de $50 \%$ da produção nacional. A milenar técnica da queimada usada pelos agricultores primitivos donos de pequenas culturas, é a mesma ainda empregada hoje $\mathrm{em}$ dia nos gigantescos canaviais, para agilizar e facilitar o trabalho de corte e desponte manual da cana na época da colheita. Além das partículas e aerossóis, as queimadas emitem para a atmosfera uma grande quantidade de gases dentre eles o dioxido de carbono, $\mathrm{CO}_{2}$, principal gás do efeito estufa, e o monóxido de carbono, CO, gás reativo e tóxico quando em concentraçōes clevadas. A emissão destes e outros gases, sob a ação ultravioleta solar, pode produzir grandes quantidades de ozônio, $\mathrm{O}_{3}$, o qual, além de tóxico, contribui também ao efeito estufa. Sob a influência do deslocamento das massas de ar, estes poluentes podem ser transportados para longe dos locais de produção, influenciando desta maneira regiōes remotas.

Para acompanhar o "boom" no mercado do álcool combustível foram necessárias várias modificaçōes no sistema de colheita e produçâo, dentre elas a melhoria, modemizaçāo e expansâo das usinas, aumento significativo das úreas plantadas e agilizaçẩo dos processos de corte e transporte de cana.

Na Tab. 1 tem-se a evolução anual da área colhi- da (milhōes de hectares, Mha), e correspondente produçâo (milhōes de toneladas, Mt) de cana-de-açúcar para o Brasil e o Estado de São Paulo, de 1975 a 1989. Estes dados estāo contidos em publicaçôes mensais do Instituto Brasileiro de Geografia e Estalística (IBGE, 1975 a 1989). Paralelamente, a partir de 1983 o Instituto de Pesquisas Espaciais (INPE) em convênio com a SERPRO e a FUNCATE, lançaram o projeto CANASATE (Mendonça et al., 1989), cujo objetivo era a obtenção, através de interpretaçân de imagens de satélite, da distribuiçâo espacial c da estimativa de área da cultura da cana-de-açúcar, utilizando técnicas de sensoriamento remoto. Verifica-se que a produçāo nacional de cana-de-açúcar cresceu 2,8 vezes $\mathrm{cm} 15$ anos enquanto que no Estado de Sāo Paulo, no mesmo intervalo de tempo, o aumento foi de 3.7 vezes, o que corresponde, desde 1984 , a cerca de $50 \%$ da produção brasileira. Notar, no entanto, que of fator de aumento na produção de álcool foi bem maior (de 500 milhōes de litros até 1975 a 12 bilhōes de litros em 1988) devido a vários melhoramentos introduzidos no cultivo da cana e nos métodos de produção. São cerca de 270 usinas em todo o pars sendo que 101 estâo-localizadas na região Norte-Nordeste e 169 na região Centro-Sul. No Estado de Sāo Paulo existem 93 usinas em funcionamento. A importância de Sâo Paulo, no que concer-

Tabela 1. Cana-de-açúcar no Brasil e no Estado de São Paulo.

Table 1. Production of sugar cane in Brazil and in the State of São Paulo.

\begin{tabular}{|c|c|c|c|c|c|c|}
\hline \multirow[b]{2}{*}{ Ano } & \multicolumn{2}{|c|}{ Brasil } & \multicolumn{2}{|c|}{ São Paulo } & \multirow{2}{*}{$\begin{array}{l}\% \text { de } \\
\text { Área } \\
\text { colhida }\end{array}$} & \multirow{2}{*}{$\begin{array}{l}\text { Sâo Paulo } \\
\text { Quantidade } \\
\text { produzida }\end{array}$} \\
\hline & $\begin{array}{c}\text { Área colhida } \\
\text { milhōes de HA } \\
\text { (Mha) }\end{array}$ & $\begin{array}{c}\text { Quantidade } \\
\text { produzida } \\
\text { (Mt) }\end{array}$ & $\begin{array}{c}\text { Área colhida } \\
\text { milhōes de HA } \\
\text { (Mha) }\end{array}$ & $\begin{array}{c}\text { Quantidade } \\
\text { produzida } \\
\text { (Mt) }\end{array}$ & & \\
\hline 1975 & 2,0 & 92 & 0,6 & 36 & $30 \%$ & $39 \%$ \\
\hline 1976 & 2,1 & 103 & 0,7 & 46 & $33 \%$ & $45 \%$ \\
\hline 1977 & 2,3 & 120 & 0,8 & 52 & $35 \%$ & $43 \%$ \\
\hline 1978 & 2,4 & 129 & - & - & - & - \\
\hline 1979 & 2,5 & 139 & 0,9 & 64 & $36 \%$ & $46 \%$ \\
\hline 1980 & 2,6 & 149 & 1,0 & 73 & $38 \%$ & $49 \%$ \\
\hline 1981 & 2,8 & 156 & 1,1 & 74 & $39 \%$ & $47 \%$ \\
\hline 1982 & 3,1 & 187 & 1,3 & 92 & $42 \%$ & $40 \%$ \\
\hline 1983 & 3,5 & 216 & 1,5 & 115 & $43 \%$ & $53 \%$ \\
\hline 1984 & 3,7 & 222 & 1,6 & 117 & $43 \%$ & $53 \%$ \\
\hline 1985 & 3,9 & 247 & 1,7 & 128 & $44 \%$ & $52 \%$ \\
\hline 1986 & 4,0 & 239 & 1,7 & 116 & $43 \%$ & $49 \%$ \\
\hline 1987 & 4,3 & 269 & 1,7 & 130 & $40 \%$ & $48 \%$ \\
\hline 1988 & 4,1 & 258 & 1,9 & 135 & $46 \%$ & $52 \%$ \\
\hline 1989 & 4,1 & 261 & 1,7 & 132 & $41 \%$ & $51 \%$ \\
\hline
\end{tabular}


ne à cana-de-açúcar, foi um dos principais motives pelo qual esta regiāo foi escolhida para realizaçâo do Projeto Fogo, sendo que os mapas do Projeto CANASATE auxiliaram na escolha da regiāo do experimento.

Existem diversas espécies de cana-de-açúcar com características distintas. Em geral, porém, e se bem tratadas, elas podem chegar a quase quatro metros de altura e ter um grande volume de folhas, de 40 a 150 toneladas/hectare (t/ha), enquanto que a maioria das outras culturas produz de 1 a 4 tha (Fernandes, 1988), isto é, a cana produz cerca de 100 vezes mais matéria orgânica fibrosa do que as outras culturas. As canas são plantadas com $1,5 \mathrm{~m}$ de espaçamento, e é realmente incrivel constatar que o canavial torna-se totalmente impenetrável à medicla que a cana cresce, tal o volume de follas:

Quander at cina amadurece sua folhagem seca, possibilita o risén de incêndios acidentais com os trabalhadores no interior do canavial, sendo este, além disso, habitat de animais peçonhentos como cobras, aranhas, etc. As probabilidades de ferimento com o facâo no corte de cana não queimada sâo maiores, devido à dificuldade de se trabalhar com palha atrapalhando a visāo. O desgaste físico do operador torna-se maior, por necessitar maior quantidade de movimentos para corte, desponte e limpeza da cana. Em 10 (dez) minutos queima-se um talhâo ( 5 hectares) de cana. A cana e cortada imediatamente após a queima, sem palha, bichos, perigo. Calcula-se que um homem pode cortar cerca de 0,5 tonelada de cana sem queimar por dia. Quando a cana é queimada antes do corte, este valor aumenta para 5 toneladas (Fernandes, 1988), isto é, dez vezes mais. Todos estes fatores são lembrados para jostificar a prática da queimada.

Por outro lado, a colheita da cana pode ser totalmente mecanizada. Iixistem hoje máquinas extremamente elicientes yue colhem a cana, separam-na da folhagen e cortant-na em pedaços de tamanho adequado, facilitando o transporte. Entretanto, por problemas sociais, técnicos, culturais, e principalmente econômi$\cos$ as colhedoras ainda nâo foram introduzidas em larga escalat. A collseila mecanizada é realizada principalmente pelá $\Lambda$ ustrália e EUA, enquanto que os demais grandes produtores, Cuba, India e Brasil, realizam it colheita manual.

\section{A FOTOQUÍMICA DO O $\mathrm{O}_{3}$ e CO}

A principal fonte de ozônio na troposfera é a produçấo fotoquínica que responde por $85 \%$ do ozônio local, enquanto que os $15 \%$ restantes sāo provenientes dat estratosfera (Fishman, 1985). Os principais gases que geram o ozónio, através da oxidação fotoquímiç, sâo o $\mathrm{C}\left(\mathrm{O}, \mathrm{CII}_{4}\right.$ c hidrocarbonctos nẩo metâ- nicos (HCNM) na presença dos óxidos de nitrogènio, $\mathrm{NO}$ e $\mathrm{NO}_{2}$. O mecunismo de oxidação para o $\mathrm{CO}$ pode ser descrito por uma das duas seqüẻncias de reaçỏes abaixo (Crutzen, 1983),

$$
\begin{aligned}
& \mathrm{CO}+\mathrm{OH} \rightarrow \mathrm{CO}_{2}+\mathrm{II} \\
& \mathrm{H}+\mathrm{O}_{2}+\mathrm{M} \rightarrow \mathrm{HO}_{2}+\mathrm{M} \\
& \mathrm{HO}_{2}+\mathrm{NO} \rightarrow \mathrm{NO}_{2}+\mathrm{OH} \\
& \mathrm{NO}_{2}+\mathrm{hv} \rightarrow \mathrm{NO}+\mathrm{O} .(\mathrm{\lambda} \leqslant 420 \mathrm{~mm}) \\
& \mathrm{O}+\mathrm{O}_{2}+\mathrm{M} \rightarrow \mathrm{O}_{3}+\mathrm{M} \\
& ---+--- \\
& \mathrm{CO}+2 \mathrm{O}_{2} \rightarrow \mathrm{CO}_{2}+\mathrm{O}_{3},
\end{aligned}
$$

onde se tem como resultado linal a produção de ozônio e dióxido de carbono, ou:

$$
\begin{aligned}
& \mathrm{CO}+\mathrm{OH} \rightarrow \mathrm{H}+\mathrm{CO}_{2} \\
& \mathrm{H}+\mathrm{O}_{2}+\mathrm{M} \rightarrow \mathrm{HO}_{2}+\mathrm{M} \\
& \mathrm{HO}_{2}+\mathrm{O}_{3} \rightarrow \mathrm{OH}+2 \mathrm{O}_{2} \\
& ------ \\
& \mathrm{CO}+\mathrm{O}_{3} \rightarrow \mathrm{CO}_{2}+\mathrm{O}_{2},
\end{aligned}
$$

onde se tem a destruiģão de ozônio.

A primeira série de reaçōes tem maior probabilidade de ocorrer em regiōes onde a concentração de NO for maior que 5 a 10 ppby (Crutzen, 1983), ou seja em regióes continentais e principalmente próximo a centros poluidores, como no presente caso em áreas de queimadas. Segundo Logan (1985) e Sillman et al. (1989), cada molécula de CO pode gerar uma molécula de ozônio ségundo a série de reações (1), enquanto que a produçâo de $\mathrm{O}_{3}$ pela oxidaçāo do $\mathrm{CH}_{4}$ pode ser tão grande quanto 3,5 e a produção final de ozônio pelos HCNM maior ainda, podendo ir de 10 a $14 \mathrm{mo}-$ Iéculas de ozônio para o butano e o pentano.

\section{MOTIVAÇĀO DO EXPERIMENTO}

Nosso maior interesse e preocupação são as queimadas que ocorrem nas regiōes da floresta Amazốnica e do Cerrado (Kirchhoff, 1988a; Kirchholf \& Marinho, 1989), pela importância global que podem ter em relaçâo ao efeito estufa e química da atmosfera. No entanto, em Kirchlioff et al. (1991), chamamos a 
atençāo para o fato de que a quantidade de matéria seca queimada nos canaviais por ano por unidade de área É cerca de 15 vezes maior que na Amazônia, isto é, 0,5 $\mathrm{kg} / \mathrm{m}^{2}$ enquanto que na Floresta Amazônica tem-se $0,03 \mathrm{~kg} / \mathrm{m}^{2}$. Quando a cana é queimada antes da coIheita, ocorre a produçāo de grande quantidade de fumaça, dependendo das condiçōes atmosféricas e estado vegetativo das plantas. Sob clima quente e seco, no canavial com grande volume de folhas secas, o fogo 6 intenso e extremamente rápido. Deste fato nasceu também nosso interesse pelo estudo das queimadas de cana, e a constataçāo de que o interior do Estado de Sāo Paulo é no momento um laboratório natural único no mundo para estes estudos. Em trabalhos anteriores Crutzen et al. (1985), Delany et al. (1985), e Greenberg et al. (1984) estudaram os efeitos das queimadas nas regiôes do Cerrado e da floresta equatorial brasileiras. Em Kirchhoff et al. (1989a), mostrou-se os perfis de $\mathrm{CO}$ e $\mathrm{O}_{3}$ obtidos durante o experimento Fogo sobre canaviais, em comparaçâo com os obtidos por Crutzen et al. (1985) sobre o Cerrado e a Selva.

Durante as queimadas ocorre a liberação de gases precursores do ozônio dentre eles o monóxido de carbono, o metano $\mathrm{e}$ hidrocarbonetos nâo metânicos os quais sob a açāo dos raios solares produzem o ozônio em grandes quantidades (Crutzen, 1983). Este fenômeno, o processo de formação de espécies gasosas, durante episódios de poluiçâo, é conhecido como "smog fotoquímico", que vem sendo muito estudado nas regiōes urbanas, onde se pode identificar mais pre- cisamente as diversas fontes poluidoras. Em Kirchloff \& Marinho (1989) e Kirchhoff et al. (1989b) mostrouse que a concentraçāo de $\mathrm{CO}$ e $_{3}$ chega a triplicar durante a cstaçâo seca na esta;āo de Cuiabá, comparada a época das chuvas, e que este fato se deve as queimadas na regiăo do Cerrado e Amazônia.

O objetivo do Projeto Fogo é de medir as quantidades de gases lançados na atmosfera quando das queimadas, e quais as consequiências que estes gases trarão para a atmosfera. As datas e os locais dos vôos que fazem parte deste experimento estão relacionados na Tab, 2. Como se sabc, o ozônio é um dos mais importantes componentes gasosos da nossa atmosfera. $\wedge$ camada de ozônio situada a cerea de $30 \mathrm{~km}$ de altitude, onde a concentração deste gás chega a 7 ppmv (partes por milhāo por volume), blinda a Terra contra a radiaçāo ultra-violeta $(280-320 \mathrm{~nm})$, letal para a vida terrestre. Este mesmo ozônio que por um lado nos protege, por outro pode ser nocivo à saúde de animais $\mathrm{c}$ plantas quando presente em altas concentraçōes nas camadas mais baixas da atmosfera, onde vivemos $e$ respiramos. A motivaçâo do Projeto Fogo é portanto muito clara. Com a existência de um fato novo (o Proálcool tem apenas 10 anos) surgiu no interior de São Paulo uma fonte nova, intensa, e periódica de produção de fumaça, gases primários $\left(\mathrm{CO}_{2}, \mathrm{CO}\right.$, etc. $)$ e gases secundários $\left(\mathrm{O}_{3}\right)$. O Projeto F'ogo concentrouse em medir esta produçāo de gases na regiāo afetada. $\mathrm{O}$ valor normal típico das concentraçôes do $\mathrm{CO} \mathrm{e}$ do $\mathrm{O}_{3}$, sem influência antropogênica (o chamado "back-

Tabela 2. Datas e locais dos experimentos: Projeto FOGO I, II e III.

Table 2. Dates and sites of the field campaigns: Project Fire I, II and III.

\begin{tabular}{|c|c|c|c|c|c|}
\hline V6o & Data & Local & Horário & Altura (pés) & \\
\hline 1 & $31 / 08 / 88$ & 7.6 .5 .4 .5 & $09: 00-11: 35$ & $1350 / 1050$ & FOGO I \\
\hline 2 & $01 / 09 / 88$ & 5.3 .1 .8 .7 & $09: 30-12: 10$ & $1350 / 1050$ & FOGO 1 \\
\hline 3 & $01 / 09 / 88$ & 7.6 .5 .4 .5 & $16: 17-17: 57$ & $2550 / 1350$ & FOGO I \\
\hline 4 & $02 / 09 / 88$ & 5.4 .3 .1 .9 & $09: 10-12: 30$ & Perfil & FOGO I \\
\hline 5 & $06 / 06 / 89$ & 7.6 .5 .4 .3 & $15: 35-17: 25$ & 1350 & FOGO II \\
\hline 6 & $07 / 06 / 89$ & 3 & $12: 30-16: 40$ & Perfil & FOGO II \\
\hline 7 & $08 / 06 / 89$ & 4 & $11: 30-15: 40$ & Perfil & FOGO II \\
\hline 8 & $19 / 09 / 89$ & 7.8 & $09: 20-12: 58$ & 6500, Perfil & FOGO 111 \\
\hline 9 & $19 / 09 / 89$ & 8-Cuiabá & $13: 45-16: 35$ & Patamares & POGO III \\
\hline 10 & $20 / 09 / 89$ & Chapada do Guimarăes & $10: 10-13: 03$ & Perfil & FOGO III \\
\hline 11 & $20 / 09 / 89$ & Cuiabá - 5 & $14: 20-17: 20$ & 9000 & FOGO III \\
\hline 12 & $21 / 09 / 89$ & 4 & $09: 25-12: 45$ & Perfil & FOGO III \\
\hline 13 & $21 / 09 / 89$ & 4 & $14: 02-16: 40$ & Perfil & FOGO III \\
\hline
\end{tabular}


ground") é de 100 ppbv para o $\mathrm{CO}$ e 20 ppbv para o $\mathrm{O}_{3}$, mas o valor exato depende do ambiente. Deve-se notar que a legislaçāo brasileira prevê concentraçôes máximas para os acima citados: 35 e 9 ppmv de $\mathrm{CO}$, respectivamente, durante uma e oito horas, e 80 ppbv de $\mathrm{O}_{3}$ durante uma hora, sendo que estes valores nāo devem ser excedidos mais de uma vez por ano (Portaria Normativa $n^{2}-348$ de $14 / 03 / 90$ ).

\section{MÉTOdOS DE MEDIDAS}

Neste projeto foram medidos os gases ozônio $\left(\mathrm{O}_{3}\right)$, monóxido de carbono $(\mathrm{CO})$, e dióxido de carbono $\left(\mathrm{CO}_{2}\right)$, além do radônio-222. Foram também feitas medidas complenentares de meteorologia de superfície e atravếs de radiossondagens.

Como plataforma móvel de aquisiçāo de dados foi usada a aeronave EMB-110-B1, o aviāo Bandeirante do INPE, de prefixo PP-FFV, que apresenta a vantagem de oferecer uma grande cobertura espacial. No aviäo foi montado um sensor de ozónio, fazendo medidas contínuas, e um sistema de coleta de amostras de ar, esporádico, para posterior análise em laboratório de gases de longa vida.

A determinaçāo do ozônio foi feita de forma contínua com analisadores que operam segundo o princípio da absorçāo de radiaçâo ultra-violeta pela molécula de ozônio cuja descrição está detalhada em Kirchhoff (I988b). O fotômetro é muito estável e sua calibração é feita trếs vezes ao dia $(8 \mathrm{~h}, 12 \mathrm{~h}$, e $16 \mathrm{~h})$. A precisāo do aparelho é da ordem de $1 \%$ e o erro na exatidâo das medidas, utilizando-se para aferiçāo um fotometro padrão, é menor que $3 \%$, O limite de deteção é 1 ppbov.

Para as amálises de $\mathrm{CO}$ e $\mathrm{CO}_{2}$ colela-se ar sob pressāo através de bombas de diafragma, no interior de cilindros de aço inoxidável previamente evacuados. Estes cilindros tem o seu interior polido eletronicamente o que impossibilita a aderência de partículas sobre suas parcules. Os cilindros são entāo, enviados ao Laboratório de O/onio do Instituto de Pesquisas Espaciais (INPL) em Sāo José dos Campos. As análises de CO sî̀ feitas através de cromatografia gasosa, descritas em Kirchihofl \& Marinho (1988, 1989). A calibraçâo absoluta do instrumento é obtida, como de praxe em métodos de cromatografia, através de comparaçāo com gases de concentração padrâo. As operaçōes sāo simples e rápidas e tem excelente resoluçāo, e a precisầ en formo de $I(K)$ pplov é $0,2 \%$.

Para as análises de $\mathrm{CO}_{2}$ os cilindros amostradores sâo conectados a um outro cromatógrafo equipado com um conversor catalítico em linha com um detetor de ionizaçâo de chama (FID). O sistema catalítico (metanizador) converte o $\mathrm{CO}_{2}$ e $\mathrm{CO} \mathrm{em} \mathrm{CH}_{4}$, e este áltimo é medido pelo detetor de ionizaçâo de chama. $O$
$\mathrm{CH}_{4}, \mathrm{CO}$ e $\mathrm{CO}_{2}$ que saem das colunas de separaçâo, passam através do conversor por meio de válvulas, isto é, automaticamente. A Fig. 1 mostra a sequêencia cromatográfica.

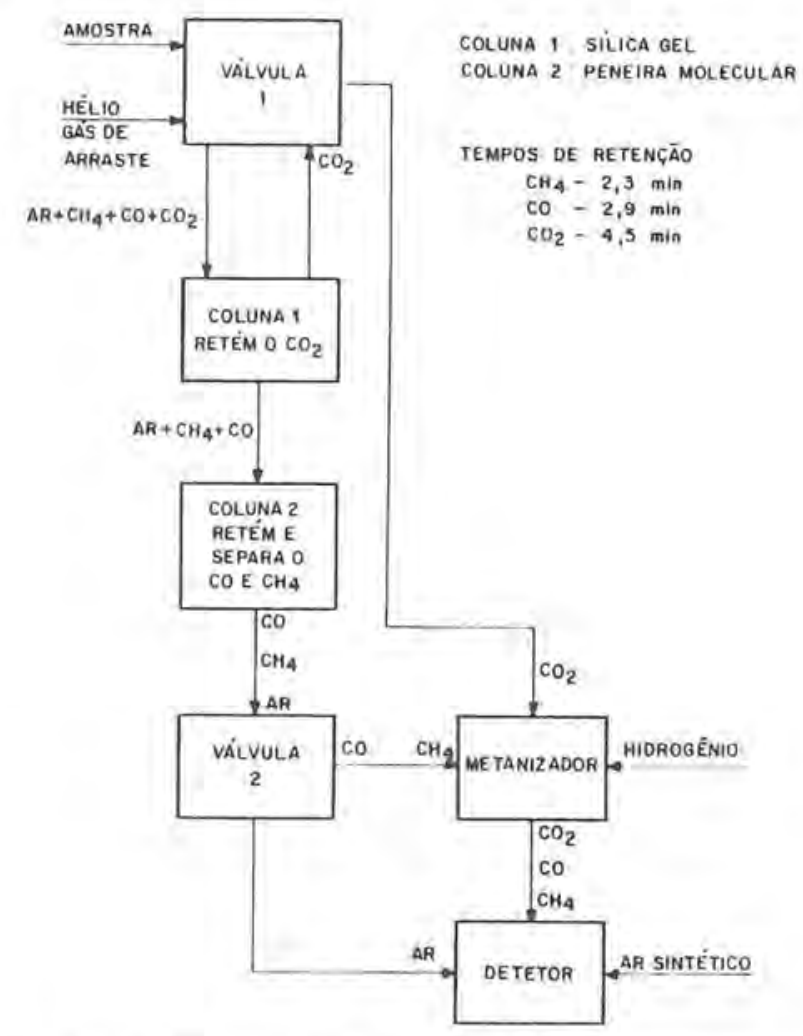

Figura 1. Esquema de válvulas e colunas do cromatógrafo a gás usado para análises de $\mathrm{CO}, \mathrm{CO}_{2}$ e $\mathrm{CH}_{4}$.

Figure 1. Valves and columns sequence of the gas cromatograph used for $\mathrm{CO}, \mathrm{CO}_{2}$ and $\mathrm{CH}_{4}$ analysis.

Introduzida a amostra no sistema, o $\mathrm{CO}_{2}$ fica retido na coluna 1 de sílica gel. $\mathrm{O} \mathrm{CO} \mathrm{e} \mathrm{CH}_{4}$ passando direto pela coluna $\mathrm{I}$, sấo retidos e separados na coluna 2 sendo que o ar vai direto para o detetor de ionização de chama. Por meio da válvula 2 o $\mathrm{CO}$ e $\mathrm{Cl}_{4}$ sāo desviados para o metanizador onde o $\mathrm{CO}$ sofre a seguinte reação:

$\mathrm{CO}+3 \mathrm{H}_{2} \rightarrow \mathrm{CH}_{4}+\mathrm{H}_{2} \mathrm{O}$

O metano é o primeiro gás detetado (tempo de retençāo 2,3 minutos), logo em seguida vem o monóxido de carbono (tempo de retenção 2,9 minutos). O tempo para o $\mathrm{CO}_{2}$ escapar da sílica gel é suficientemente longo para permitir a deteção do $\mathrm{CO}$ e $\mathrm{CH}_{4}$. Após a passagem do $\mathrm{CO}$ e $\mathrm{CH}_{4}$, a seqüència de válvulas é mudada automaticamente deixando o gás $\mathrm{CO}_{2}$ ir diretamente para o metanizador onde ocorre a 
reação:

$\mathrm{CO}_{2}+4 \mathrm{H}_{2} \rightarrow \mathrm{CH}_{4}+2 \mathrm{H}_{2} \mathrm{O}$

e finalmente para o FID (tempo de retençāo do $\mathrm{CO}_{2} \sim 4,5$ minutos)

As concentraçōes de $\mathrm{CO}_{2}$ em torno de aproximadamente 330 ppmv estāo dentro da faixa dos limites бtimos de sensibilidade do detetor de ionização de chama. Para calibraçäo do $\mathrm{CO}$ e $\mathrm{CO}_{2}$ utilizou-se o padrāo de $\mathrm{R}$. Rasmussen da Universidade de Oregon, EUA.

Os dados meteonologicos de superfficie foram fornecidos pela UNESP - Campus de Jaboticabal, pelo Instituto Meteorológico de Bauru e pelo Instituto Nacional de Meteorologia (INEMET). Radiossondagens feitas duas vezes ao dia durante os dias de vôo em Bauru foram usadas para o cálculo de trajetórias de massas de ar.

\section{ESTAÇÕES DE SUPERFICIE}

As regiōes do Estado de Sâo Paulo onde a canade-açúcar é cultivada sāo mostradas na Fig. 2. Os locais escolhidos para instalaçăo das bases de apoio de solo foram Jaboticabal (ponto 4, Fig. 2), que está situada em uma regiâo de grande concentração canaviei$\mathrm{ra}$, e onde contou-se com o apoio de pesquisadores da

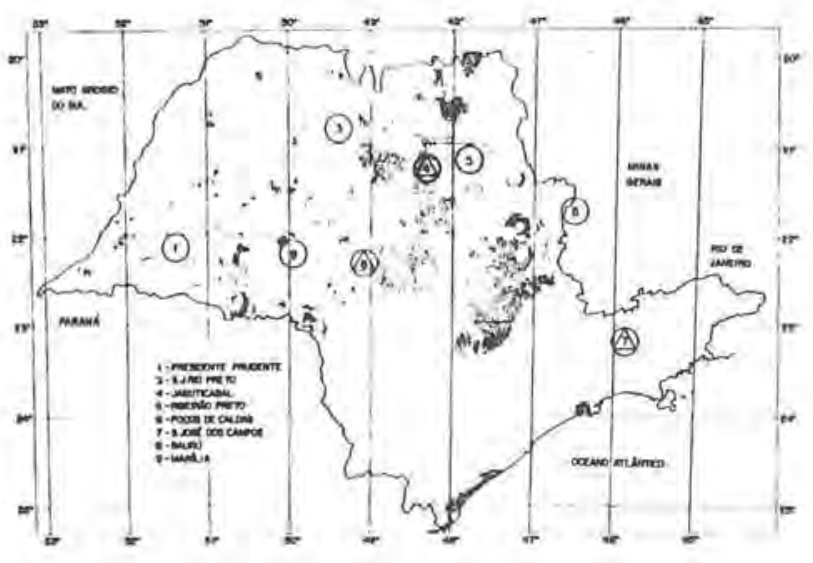

Figura 2. Mapa do Estado de Sāo com a grade de latitude-longitude, onde as áreas sombreadas representam regiôes canavieiras. Os triângulos circunscritos mostram a localização das estaçốes de superfície e os ćrculos alguns pontos de referência.

Figure 2. Map of the state of São Paulo with latitudelongitude grid, where the dashed areas represent the sugar cane region. The triangles show the location of surface stations and some reference points are shown by the circles.
UNESP - Campus de Jaboticabal. A outra base foi Bauru onde contou-se com o aproio logístico do Instituto Meteorológico de Bauru. Bauru, ponto 8 da Fig. 2 , encontra-se fora das regiôes canaviciras, mas normalmente recebe massas de ar que vem das regiōes queimadas. Nos dois institutos foram instalados sensores de ozônio de superfície que permaneceram em operação durante o Projeto Fogo 1 de 28 de agosto a 07 de setembro de 1988, Fogo II de 29 de maio a (N) de junho 1989, e Fogo III de 04 a 22 de setembro de 1989. Em Bauru foram realizadas radiossondagens, duas vezes ao dia, uma pela manhấ c outra à tarde, durante a semana de vóos dos Projetos Fogo I e II.

O Laboratório de Ozónio do INPE 6 o centro de atividades onde estão alocados os pesquisadores e pessoal técnico do Projeto $\mathrm{e}$ os demais equipamentos de medida utilizados. Neste laboratório sâo feitas medidas rotineiras de ozônio de superfície, sendo analisadas amostras de ar coletados em diversas estaçōes de superfície do país, inclusive Cuiabá, que foi uma estação base no Projeto Fogo III. Nas dependências do INPECuiabá sāo também realizadas medidas rotineiras de ozônio de superfícic e amostragens de ar em cilindros que sāo posteriormente remetidos ao laboratório de São José dos Campos

\section{ESTRATÉGIA DE TRABALHO}

Os experimentos Fogo I e III foram realizados durante a estaçāo seca quando os índices pluviométricos sâo muito baixos permitindo a ocorrencia de quei-

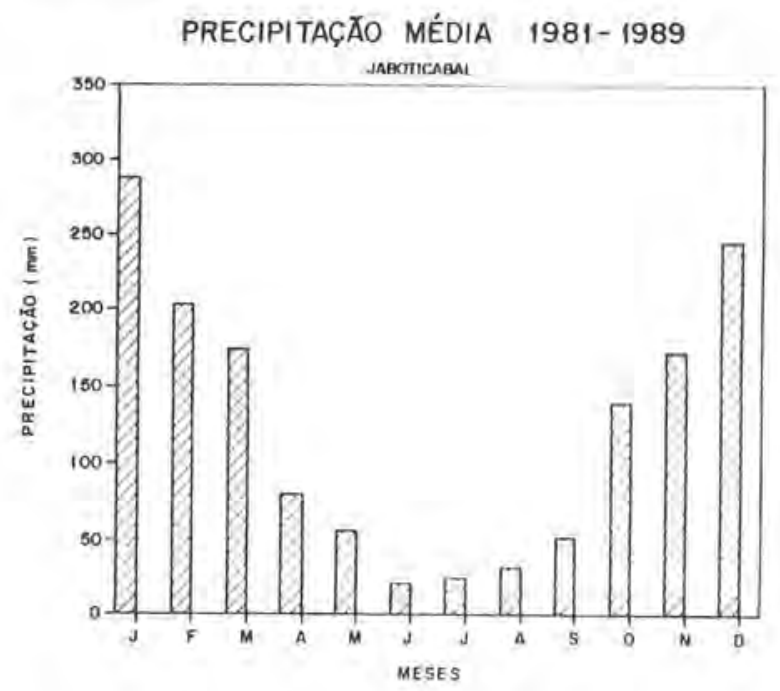

Figura 3. Precipitação média mensal no período de $198 \mathrm{I}$ a 1989 , sobre a cidade de Jahoticabal.

Figure 3. Mean monthly precipitation for the 1981 to 1989 period, for Jaboticabal. 
madas, A Fig. 3 mostra a média de precipitação na região de Jaboticabal, para o período de 1981 a 1989 , onde se observa nitidamente que os meses mais secos são junho, julho, agosto e setembro. Embora estes experimentos, liogo I e III, tenham ocorrido na mesma época do ano, as condiçôes meteorológicas foram distintas: durante agosto e setembro de 1988 a precipitaçâo foi zero em várias regiôes do país em particular nas regiōes de Jaboticabal e Bauru. Nesta época foi decretado estado de alerta em todo o Estado de São Paulo, com a proibição expressa das queimadas. No ano seguinte, pelo contrário, o experimento teve que ser adiado tal a quantidade de chuva. Na Fig. 4 tem-se a precipitaçāo diária no mês de setembro de 1989 para Jaboticabal e Bauru, onde se verifica a ocorrência de fortes precipitaçōes em Bauru até meados do mês de setembro.

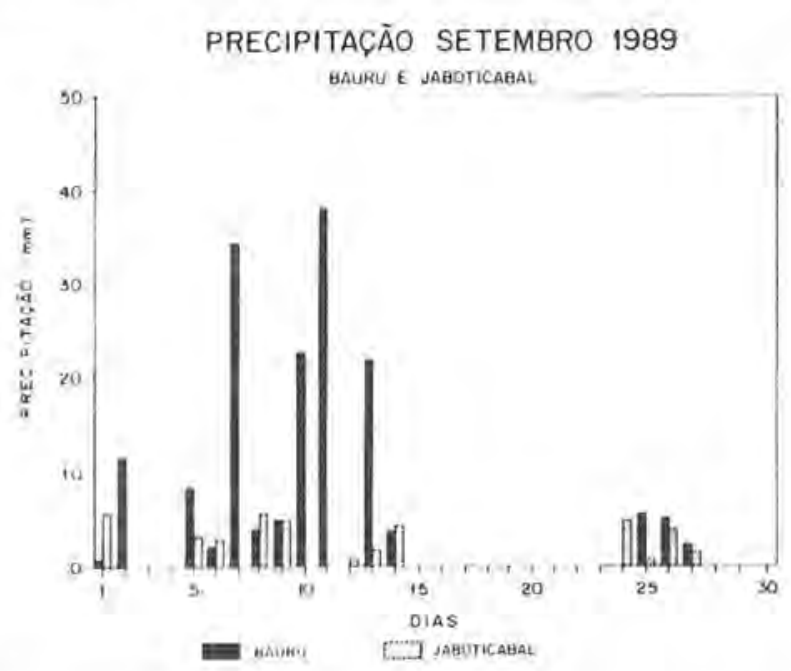

Figura 4. Precipitaçồes diárias ocorridas em Jahoticabal c Bauru durante o mês de setembro de 1989.

Figure 4. Daily precipitation in Jaboticabal and Bauru during September 1989.

O experimento logo 11 teve lugar no final da estaçấo chuvosa de 1989, quando as queimadas em grande escala ainda não haviam começado. O objetivo deste experimento foi o de observar a concentração de gases durante este período, para efeito de comparaçâo com os resultados da época de queimadas.

\section{RESULTADOS E DISCUSSÃO}

\section{Estação chuvosa}

A Fig. 5 mostra os perfis verticais do $\mathrm{CO}, \mathrm{CO}_{2}$ e $\mathrm{O}_{3}$, obtidos nos dias 07 e 08 de junho de 1989 , no fi- nal da estaçăo chuvosa, respectivamente em Sâo José do Rio Preto (ponto 3, Fig, 2), e em Jaboticabal (ponto 4, Fig. 2), este último sobre região canavieira. Uma das características mais marcantes destes perfis é a praticamente constância em toda troposfera das concentraçōes dos gases $\mathrm{CO}(75 \pm 21 \mathrm{ppbv}), \mathrm{CO}_{2}(349 \pm$ 3 ppmv) e $\mathrm{O}_{3}$ ( $26 \pm 5$ ppbv) que é o resultado esperado de uma atmosfera bem misturada, em regime de chuvas. Estas concentraçōes obtidas para o Fogo II correspondem às concentraçōes de uma atmosfera limpa, isto $\hat{E}$, podem ser consideradas o "background".
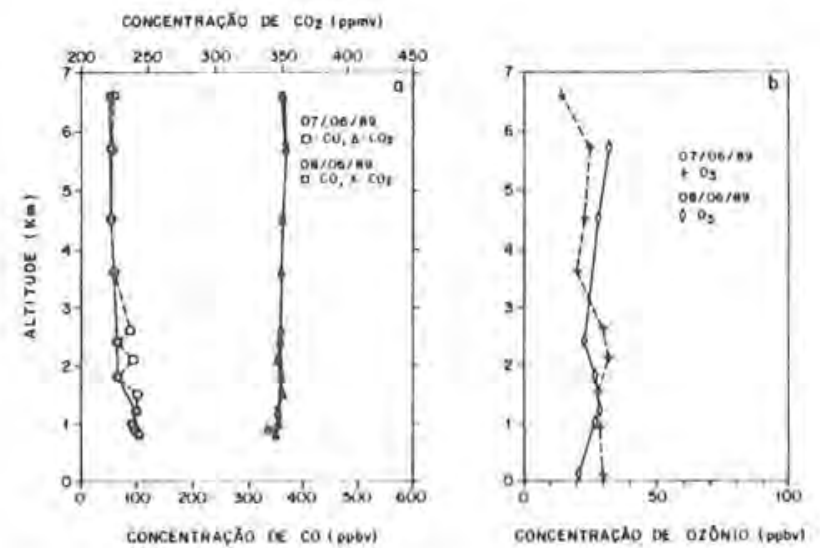

Figura 5. Perfis verticais do: a) monoxido e díbxido de carbono e b) ozônio, obtidos durante o experimento Fogo II.

Figure 5. Vertical profiles of: a) carbon monoxide and carbon dioxide and b) ozone during the field campaign Fire 11.

\section{Estaçāo seca}

Na Fig. 6 estāo plotados os perfís de $\mathrm{CO}$, obtidos durante os Projetos Fogo I e III, estaçāo seca, conforme mostra a Tab, 2. Verifica-se uma grande diferença nas concentraçōes de $\mathrm{CO}$ obtidas nestes experimentos, sendo que, abaixo de $3,5 \mathrm{~km}$ de altitude, no Fogo I (curva 1) as concentraçōes chegam a ser três vezes maiores que as curvas 3 e 4 . Isto se deve a dois fatores principais. O primeiro foi que nos dois meses que precederam o Fogo $\mathrm{I}$, năo ocorreram precipitaçōes no Brasil Central (Boletim Agroclimatológico, 1988) incluindo Sâo Paulo, o que fez com que a atmosfera ficasse saturada de poluentes, enquanto que no Fogo III (Boletim Agroclimatológico, 1989), conforme mostrou-se na Fig. 3, o total de chuva no mês de agosto e nos dias de setembro que precederam o experimento, foi de $50,1 \mathrm{~mm}$ em Jaboticabal, $179,7 \mathrm{~mm}$ em Bauru e $129,5 \mathrm{~mm}$ (total de agosto e setembro) em Cuiabá. 
Estas chuvas além de "limpar" a atmosfera dificultaram as queimadas.

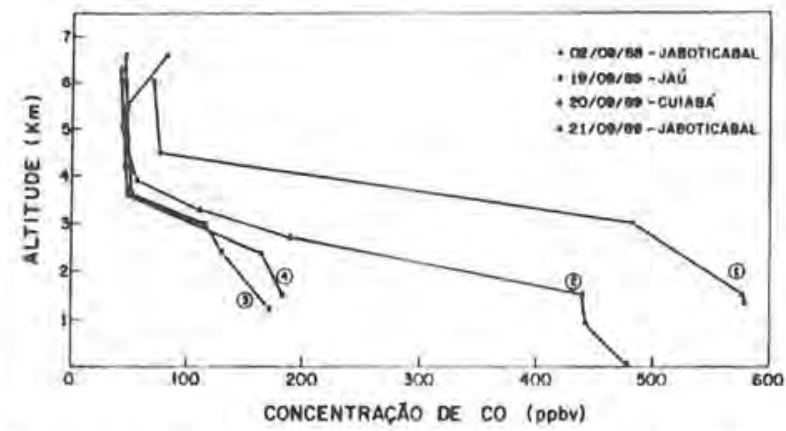

Figura 6. Perfis verticais do mon6́xido de carbono obtidos durante a estaçāo seca, experimentos Fogo I e III.

Figure 6. Vertical profiles of carbon monoxide obtained during the dry season of the field campaigns Fire I and III.

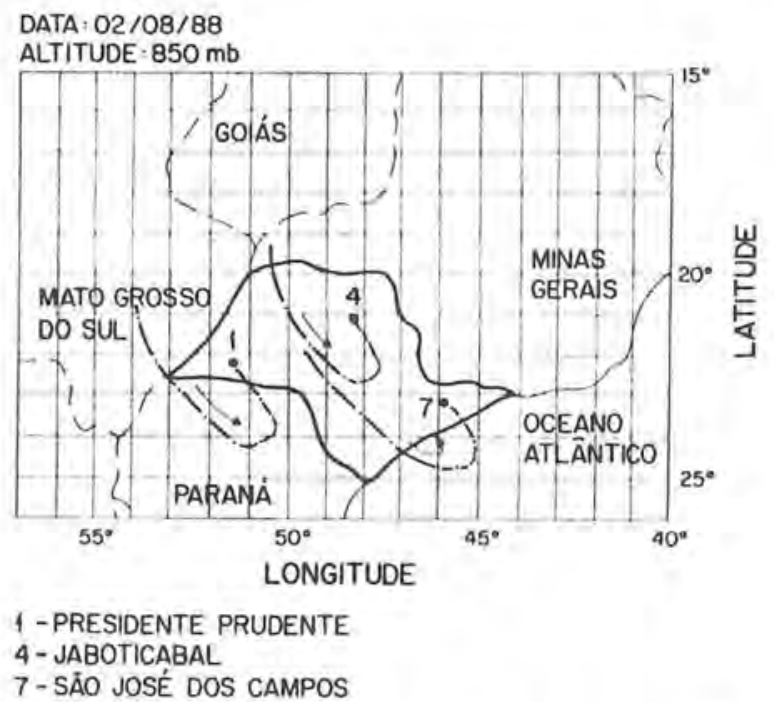

Figura 7. Trajetórias das massas de ar com pontos finais em Presidente Prudente (ponto 1), Sāo José dos Campos (ponto 7) e Jaboticabal (ponto 4), para o dia 2 de setembro de 1988. Os símbolos foram plotados com intervalos de 5 horas.

Figure 7. Air mass trajectories, with end points at Presidente Prudente (point 1), São José dos Campos (point 7 ) and Jaboticabal (point 4), for September 2nd 1988. The symbols were plotted with 5 hours interval.

As Figs. 7 e 8 mostram que o segundo, e mais importante fator para a diferença de concentraçöes obtidas no Fogo I e III, foi que as massas de ar para estes experimentos tiveram origens diferentes. A Fig. 7 mostra as trajetórias das massas de ar com pontos finais em Presidente Prudente, Jaboticabal, c São José dos Campos (pontos 1, 4 e 7 respectivamente da Fig. 2), obtidas no dia 02 de setembro de 1988 , Fogo I, ao nível de 850 milibares ( $\mathrm{mb}$ ), aprnximadamente a 1500 $m$ acima do nível do mar. Nesta ligura verifica-se que estas massas de ar originam-se sobre a região do $\mathrm{Cer}$ -

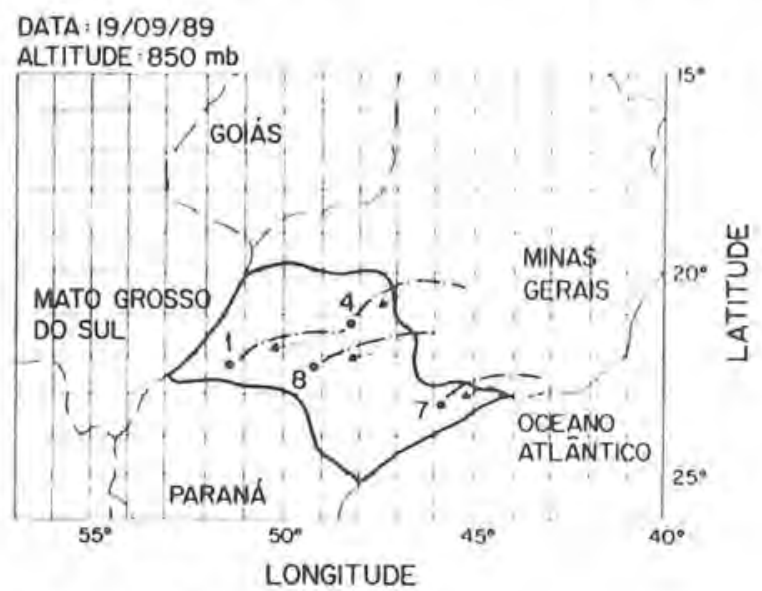

1 -PRESIDENTE PRUDENTE

4- JABOTICABAL

7-SĀO JOSÉ DOS CAMPOS

8-BAURU

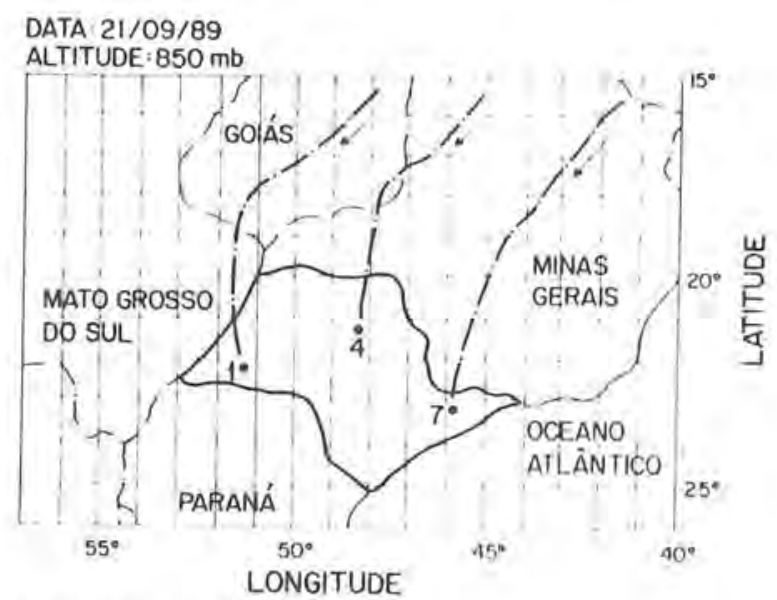

1 - PRESIDENTE PRUDENTE

4-JABOTICABAL

7-SÁO JOSÉ DOS CAMPOS

Figura 8. Trajetorias das massas de ar com pontos finais em Presidente Prudente (ponto 1), São José dos Campos (ponto 7) e Jaboticabal (ponto 4). Os símbolos foram plotados com intervalos de 5 horas: a) dia 19 de setembro de 1989 ; b) dia 21 de setembro de 1989.

Figure 8. Air mass trajectories with end points at Presidente Prudente (point 1), São José dos Campos (point 7) and Jaboticabal (point 4). The symbols were plotted with 5 hours interval: a) September 19, 1989; h) September 21, 1989. 
radu (ver lïg. I0) onde também ocorrem grandes queimadas nesta estação do ano. Na Fig. 8 tem-se as trajetórias para os dias 19 e 21 de setembro de 1989 (Figs. 8a, 8b), com pontos finais em Presidente Prudente, Jaboticabal e Sâo José dos Campos, a $850 \mathrm{mb}$. Estas massas de ar fazem parte de um sistema proveniente do oceano trazendo portanto ar limpo (Abreu, 1985). Tem-se, portanto, que a curva 1 da Fig. 6 (Fogo I) representa o monóxido de carbono produzido pelas queimadas Iocais somado à contribuiçāo devida às queimadas no Cerrado. As curvas 3 e 4 representam melhor a produçâo de $\mathrm{CO}$ pelas queimadas locais apenas, e a curva 2, cujo perfil foi realizado na regiâo do Cerrado próximo a Cuiabá, representa a produção deste gás pelas queimadas que lá ocorrem. Ou em resumo, pelo deslocamento das massas de ar, distinguem-se três situaçốes:

1. Fogo II: final da estação chuvosa, atmosfera limpa, "background";

2. Fogo III: estaçāo seca, contribuição de queimadas locais;

3. Fogo I: estaçâo seca, com contribuição de queimadas locais, além de uma contribuição diluída proveniente do Cerrado

Apesar das diferenças de vegetaçâo, os canaviais e Cerrados tem cáracterísticas em comum. A Tab. 3 mostra alguns parâmetros relacionados à queima para efeito de comparação. Verifica-se que a massa média e as temperaturas durante as queimadas, para Cerrado e canavial são semelhantes. O fogo se propaga com grande velocidade entre a palha dos canaviais e do Cerrado e a rápida queda da temperatura após o fogo permile o corte da cana imediatamente após as quei- madas, Segundo Foster et al. (1980), a temperatura dentro do colmo da cana a 1,5 mm da superfície externa chega a quase $100^{\circ} \mathrm{C}$, e a $2,5 \mathrm{~mm}$ a pouco mais de $50^{\circ} \mathrm{C}$

Levando-se em conta que a cana se assemelha aos arbustos queimados no cerrado, é interessante comparar a quantidade de massa seca queimada, $M$, nos canaviais e na região do Cerrado. A área total do Cerrado é de $2 \times 10^{6} \mathrm{~km}^{2}$ dos quais sāo queimados anualmente de 10 a $20 \%$ (Delany et al., 1985) usandose para o cálculo abaixo, o valor médio de $15 \%$. A densidade de biomassa na regiāo do Cerrado é de 2 $\mathrm{kg} / \mathrm{m}^{2}$ dos quais $63 \%$ ficam acima da superfície, e a eficiência efetiva de queima é de $66 \%$ (dados de Seiler \& Crutzen, 1980, Tabs, I e VI). A biomassa queimada no Cerrado é, portanto:

$M=A_{d} \times P_{q} \times D_{m} \times P_{s} \times E$,

onde $\mathrm{A}_{\mathrm{d}}$ é a área disponível, $\mathrm{P}_{\mathrm{q}}$ a porcentagem queimada, $D_{m}$ a densidade de biomassa, $P_{S}$ a porcentagem acima da superfície, e $\mathrm{E}$ a eficiência de queima. $\mathrm{O}$ resultado é

$M=249,5 \mathrm{Mt}$ de massa seca queimada,

onde Mt designa milhôes de toneladas.

Fazendo-se cálculo semelhante para os canaviais, $\operatorname{com} A_{d} \times P_{q}=4,1 \times 10^{10} \mathrm{~m}^{2}, D_{m} \times P_{s}=0,5 \mathrm{kgm}^{-2}$, e $\mathrm{E}=0,9$

$M=18,4 \mathrm{Mt}$ de massa seca queimada.

Vê-se, portanto, que a massa seca queimada nos

Tabela 3. Bíonassa acima da superfície, massa média e temperaturas durante o fogo para diferentes ecossistemas.

Table 3. Above surface biomass, mean mass and temperatures during the fire for different ecosistems.

\begin{tabular}{|c|c|c|c|c|c|c|}
\hline & \multirow{2}{*}{$\begin{array}{c}\text { Área no Brasil } \\
\qquad\left(\mathrm{km}^{2}\right)\end{array}$} & \multirow{2}{*}{$\begin{array}{l}\text { Biomassa acima } \\
\text { do solo }(\%)(\mathrm{a})\end{array}$} & \multirow{2}{*}{$\begin{array}{l}\text { Densidade superficial } \\
\qquad \mathrm{kg} / \mathrm{m}^{2(a)}\end{array}$} & \multicolumn{3}{|c|}{ Temperatura durante queimadas $\left({ }^{\circ} \mathrm{C}\right)$} \\
\hline & & & & $\begin{array}{l}\text { Topo das } \\
\text { chamas }\end{array}$ & $\begin{array}{l}\text { Centro das } \\
\text { chamas }\end{array}$ & $\begin{array}{c}\text { Superfície } \\
\text { do sola }\end{array}$ \\
\hline Canaviais & $4,1 \times 10^{4}$ & 73 & $0,5^{(e)}-1$ & $400(c)$ & $400^{(c)}$ & \\
\hline Cerrado & $2 \times 10^{6}$ & 63 & 2 & $600-800(b)$ & $300-400^{(b)}$ & $70-90^{(b)}$ \\
\hline Floresta & $5 \times 10^{6}$ & 81 & 39 & & $600^{(d)}$ & $450^{(d)}$ \\
\hline
\end{tabular}

a) Seiler \& Crutzen (1980); b) Coutinho (1980); c) Foster et al. (1980); d) Raison et al. (1986); e) Kirchhoff et al. (1989a) 
canaviais é da ordem de $7 \%$ da quantidade queimada nos cerrados.

A quantidade de $\mathrm{CO}$ emitido nas queimadas acima, pode ser estimada seguindo-se o procedimento padráo. Para tal multiplica-se a massa seca pelo fator 0,45 obtendo-se a massa equivalente de carbono, ou em termos de massa de $\mathrm{CO}_{2}$, multiplica-se ainda pelo fator 44/12 (Seiler \& Crutzen, 1980). Observa-se que $10 \%$ da massa de carbono corresponderá, em média, à massa de CO (Crutzen et al., 1985). As queimadas dos canaviais tem, portanto, o potencial de liberar para a atmosfera uma quantidade de $0,8 \mathrm{Mt}$ de $\mathrm{CO}$ por ano, da ordem de 0,3 Mt somente no Estado de São Paulo.

A contribuição das queimadas do Cerrado para a concentração de $\mathrm{O}_{3}$ observada sobre os canaviais segue o mesmo raciocínio do caso do CO. Na Fig. 9a (Fogo I), tem-se a contribuiçẫo de $\mathrm{O}_{3}$ produzido no local, mais o proveniente do Cerrado. A Fig. $9 b$ mostra a contribuiçāo principalmente das queimadas de canade-açúcar, e em 9c tem-se um perfil típico devido às queimadas do Cerrado.

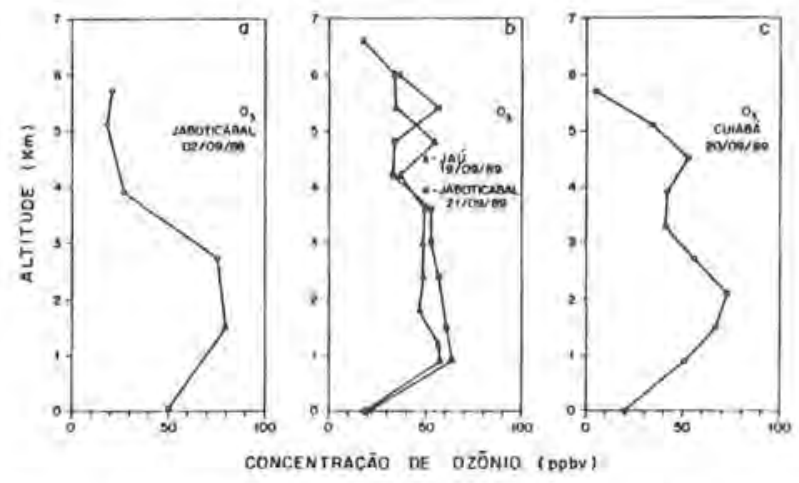

Figura 9. Perfis verticais de ozônio obtidos durante as estaçōes secas de 1988 e 1989 realizados respectivamente em: a) Jaboticabal dia 2 de setembro de 1988 , b) Jaú dia 19 de setembro de 1989 e c) Cuiabá dia 20 de setembro de 1989.

Figure 9. Ozone vertical profiles obtained during the dry seasons of 1988 and 1989, respectively; a) Jaboticabal, September 2, 1988; b) Jaú, September 19, 1989 and c) Cuiabá, September 20, 1989 .

Os perfis de ozônio mostrados na Fig. 9 mostram uma característica comum que é a diminuição na sua concentração a partir de aproximada.nente $1 \mathrm{~km}$ de altitude para baixo, o que identifica o solo como um sumidouro para este gás. Entre aproximadamente 1 e 3,5 $\mathrm{km}$ de altitude, há um pico no perfil de ozônio devido a dois processos principais: produção fotoquímica local ou transporte de cima para baixo, ou ambos. Abaixo de $3,5 \mathrm{~km}$, o excesso de concentração de $\mathrm{O}_{3} \mathrm{em}$ relaçâo à estação chuvosa, varia de 0 a 50 ppbv.

Durante a estação seca ocorre, em toda a regiâo central do Brasil, uma subsidência que dificulta a mistura das camadas de ar mais baixas com a troposfera livre, como pode ser observado pelo gráfico de $\mathrm{CO}$, Fig. 6 nos Projetos 1 e III, quando acima de cerca de $3,5 \mathrm{~km}$ de altitude tem-se níveis de concentraçāo mais baixos, característicos de uma troposfera livre em que ainda não há sinais de queimadas.

Para os três perfis obtidos no Fogo III, Figs. $9 \mathrm{~b}$ e $9 c$, observa-se um segundo pico na coneentraçăo de oz6́nio, acima de aproximadamente $4 \mathrm{~km}$ de altitude, devido a transportes de massas de ar.

\section{Excursão à Cuiabá}

Durante a época da seca, de junho a setembro, ocorrem queimadas sistemáticas no Cerrado, seja para limpeza e plantio, renovaçâo do pasto, ou por acidente. Durante este mesmo período ocorrem também as queimadas da regiāo Amazônica cujo ar pode em parte ser transportado para a região do Cerrado. A Fig. 10 mostra a localizaçâo de Cuiabá $\left(15^{\circ} 30^{\circ} \mathrm{S}, 56^{\circ} \mathrm{W}\right) \mathrm{em}$ pleno Cerrado brasileiro. O Cerrado brasileiro ocupa cerca da quinta parte do território nacional predominando nos Estados de Mato Grosso, Mato Grosso do Sul, Goiás e Tocantins e aparecendo na Bahia, Minas Gerais e Sāo Paulo. A vegetaçāo é caracterizada essencialmente por árvores pequenas ( 3 a $6 \mathrm{~m}$ de altura), com troncos retorcidos e vegetaçâo rasteira, arbustos e capim.

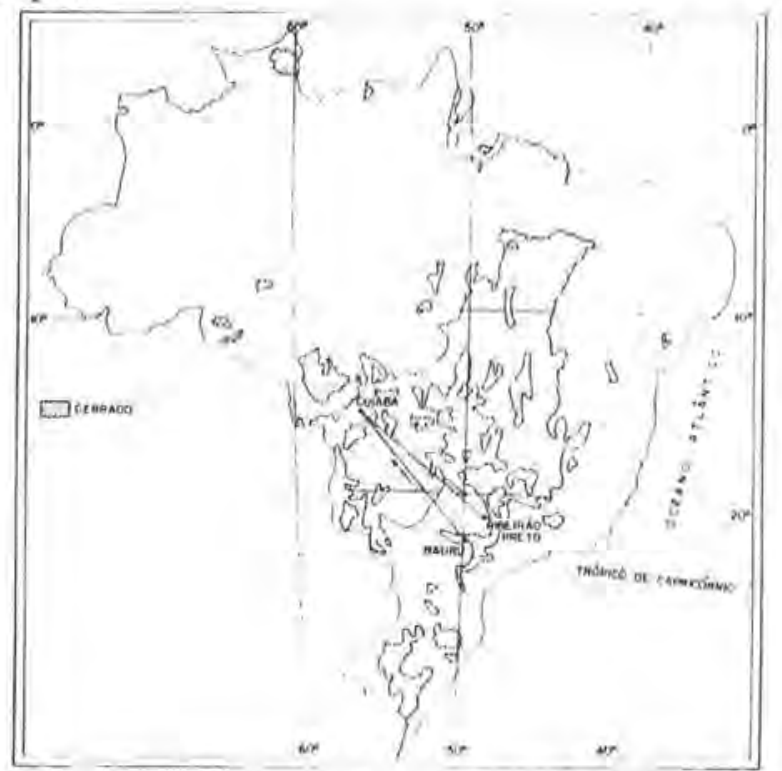

Figura 10. Mapa do Brasil mostrando as regiôes de Cerrado brasileiro, sombreado, e as trajetórias de ida, de Bauru a Cuiabá, e volta para Ribeirāo Preto.

Figure 10. Map of Brazil showing the Cerrado region, hatched, and the flight track from Bauru to Cuiabá, and back to Ribeiráo Preto. 
Com o objetivo de analisar qual a influência das queimadas do Cerrado sobre as regiōes canavieiras, foram realizados nos dias 19 e 20 de setembro de 1989 , vôos em direçāo $\mathrm{a}$, e sobre a região de Cuiabá. Na viagem de ida entre Bauru e Cuiabá (dia 19 de setembro de 89), o vôo foi realizado em patamares de 100 $\mathrm{km}$ de extensão, com duraçẩo de 10 minutos, entre 4500 e $10500 \mathrm{~m}$ de altitude, em intervalos de $2000 \mathrm{~m}$. Ao todo foram nove patamares nos quase $1200 \mathrm{~km}$ percorridos, mostrados na Fig. 11a1. O objetivo destes patamares era o de verificar qual a variaçâo da concentraçāo dos gases $\mathrm{CO}, \mathrm{O}_{3}$ e $\mathrm{CO}_{2}$ dentro da camada de mistura e com a penetraçāo no Cerrado. Na volta de Cuiabá para Bauru o aviâo manteve-se a uma altitude constante de $9000 \mathrm{~m}$, devido à total falta de visibilidade produzida pelo "smog" fotoquímico. As Figs. $11 \mathrm{~b}, \mathrm{c}, \mathrm{d}$ mostram respectivamente as concentraçōes de $\mathrm{CO}$ e $\mathrm{CO}_{2}$ nos percursos de ida e volta, $\mathrm{eO}_{3}$ apenas na ida.

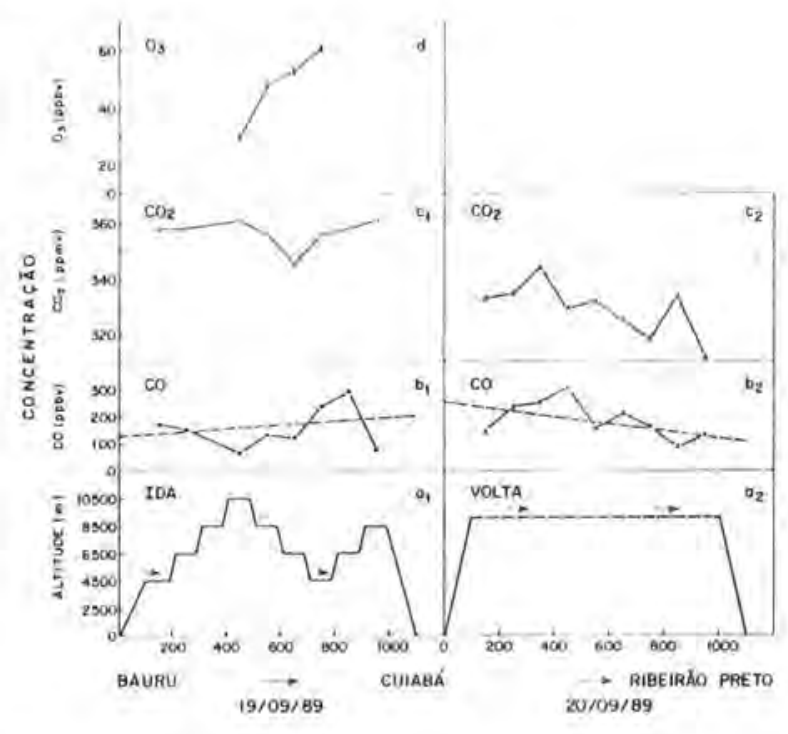

Figura 11. Esquema mostrando os trajetos de ida (a1), entre Bauru e Cuiabá, realizado em patamares de aproximadamente $100 \mathrm{~km}$ de extensăo entre 4500 e $10500 \mathrm{~m}$ de altitude com intervalos de $2000 \mathrm{~m}$, e volta (a2) à altitude constante de 9000 $\mathrm{m}$. Acima tem-se os gráficos das concentraçōes dos gases $\mathrm{CO}$ (b1 e b2), $\mathrm{CO}_{2}$ (c1 e c2) e $\mathrm{O}_{3}$ (d) na ida.

Figure 11. Results of the flight from Bauru to Cuiaba (a1), made in steps of $100 \mathrm{~km}$, approximately, between 4500 and $10500 \mathrm{~m}$ altitude with intervals of about $2000 \mathrm{~m}$ and back (a2) at 9000 $\mathrm{m}$ altitude. Concentrations are shown for $\mathrm{CO}$ (b1 and $\mathrm{b} 2), \mathrm{CO}_{2}$ (c1 and $\mathrm{c} 2$ ) and $\mathrm{O}_{3}$ (d) on the way to Cuiabs.
Verifica-se pelo gráfico da Fig. $11 \mathrm{bl}$ para o CO, uma correlaçẩo com as subidas e descidas dos patamares: quando se sobe a concentraçăo de $\mathrm{CO}$ diminui e quando se desce ela aumenta. Superposto a isto tem-se um visível aumento na concentraçāo deste gás conforme se penetra no Cerrado acercando-se de Cuiabá, ou no trajeto de volta saindo do Cerrado. Grosseiramente, adaptando retas de regtessão linear às Figs. 11 b1 e b2, na ida e na volta, tem-se:
$\mathrm{CO}=0,064 \mathrm{~d}+130.9$ (valor calculado para o trajeto de ida)

e

$\begin{aligned} \mathrm{CO}= & -0,13 \mathrm{~d}+254,1 \text { (valor calculado para o trajeto } \\ & \text { de volta) }\end{aligned}$

com CO em ppbv e d (distância do aviấo ao ponto de partida), em $\mathrm{km}$, ou seja, na ida para a região das queimadas do Cerrado, a concentraçāo de $\mathrm{CO}$ aumentou de 6,4 ppbv a cada $100 \mathrm{~km}$ e na volta caiu de 254 ppbv em Cuiabá para 111 ppby em Ribeirão Preto. (Notar que as alturas amostradas sāo diferentes). Conforme mostrado na Fig. 6 e pela análise acima, a contribuição das queimadas do Cerrado sobre a regiāo dos canaviais pode chegar a $50 \%$, sendo este um limite superior. $\mathrm{O} \mathrm{CO}_{2}$ permaneceu praticamente constante na Fig. 11 cI porém na Fig. 1Ic2 observa-se uma nitida diminuição com a sarda do Cerrado. A concentração de ozônio também aumentou com a penetraçāo no Cerrado.

\section{CONCLUSÔES}

Descrevem-se medidas a bordo de aviāo, num total de seis vôos em altitudes variadas e sete perfis verticais em diferentes locais, dos gases ozônio, monóxido e dióxido de carbono na regiâo canavieira e Cerrado, no final da estação chuvosa de 1989 (junho) e nos períodos secos de 1988 e 1989 (setembro).

As queimadas representam uma intensa fonte de $\mathrm{CO}$ e $\mathrm{CO}_{2}$ enquanto que o oź́nio é produzido fotoquimicamente na atmosfera. $\mathrm{O}$ aumento na concentração destes gases variou de três a seis vezes durante as queimadas com relaçâo a estação chuvosa quando a atmosfera está limpa devido a ocorrência de chuvas e pela ausência de queimadas.

Durante o primeiro experimento em setembro de 1988, através da análise de trajetórias, identificou-se massas de ar provenientes do cerrado que contribuiram, neste caso, com cerca de 30 a $50 \%$ dos poluentes sobre os canaviais. Em setembro de 1989 os ventos foram provenientes do oceano podendo-se, deste modo, 
avaliar a ação das queimadas locais. A produção de monóxido de carbono durante as queimadas de canade-açúcar é de $0,8 \mathrm{Mt}$ por ano que representam $7 \%$ da produçâo deste gás pelas queimadas do Cerrado. De acordo com Kirchhoff (1990), a produçâo global de $\mathrm{CO}$ por queima de biomassa é de $62,8 \mathrm{Mt}$ por ano sendo, portanto, $1,3 \%$ devido às queimadas de canaviais brasileiros. Devemos acrescentar finalmente, que embora haja uma forte liberaçăo de $\mathrm{CO}_{2}$ pelas queimadas de palha de cana, este $\mathrm{CO}_{2}$ não contribui a médio e longo prazo ao efeito estufa, pois uma quantidade equivalente deste gás é retirado da atmosfera via fotossíntese durante o crescimento do canavial no ano seguinte.

\section{AGRADECIMENTOS}

Somos gratos aos colegas Maria Angélica de Jesus, responsável pelas analises das amostras e reduçẩo de dados; à participaçāo nos trabalhos de campo e supervisăo técnica dos engenheiros Luiz Fernando Ribeiro e Ailton Takashima, e dos meteorologistas Dr. Pedro Dias, o qual auxiliou nas análises de trajetórias de massas de ar, e Paulo Etchichury. Aos pilotos Pedro Celso e Luiz Monteiro e ao técnico Amauri Villarino; ao apoio dos membros do Instituto Meteorológico de Bauru, em particular ao Professor Calheiros, e do Instituto de Física da UNESP - Campus de Jaboticabal, em particular aos Drs. Romísio André e Clóvis Volpe: às informaçōes e trocas de idéias com o Dr. Alberto Setzer, Antonio Formaggio, e Marcos Pereira. Ao precioso apoio dos demais membros do grupo de ozónio Rómulo Barreira e Yukitaka Nakamura, e ao Adilson Palone do INPE-Cuiabá. O presente trabalho foi financiado pela Fundaçāo de Amparo à Pesquisa do Estado de São Paulo (FAPESP), que mais uma vez desempenhou o seu papel exemplarmente.

\section{REFERÊNCIAS}

ABREU, M.L. - 1985 - Previsores sin6tico-meteorol6gicos para a dispersão de poluentes na regiāo da Grande Sâo Paulo, SP. Dissertaçáo de mestrado, Instituto Nacional de Pesquisas Espaciais, 131 p., Sáo José dos Campos, SP.

BOLETIM AGROCLIMATOLÓGICO - 1988 - Brasília, 22, nำ 1 a 12.

BOLETIM AGROCLIMATOLÓGICO - 1989 - Brasília, 2, n's, 1 a 12.

COUTINHO, L.M. - 1980 - As queìnadas e seu papel ecol6gico. Brasil Florestal, 44: 7-23.

CRUTZEN, P. - 1983 - Atmospheric interactions - homogeneous gas reactions of $C, N$, and $S$ containing compounds. In: Scope (B. Bolin \& R. Cook, eds.), John Wiley \& Sons, 67-114.

CRUTZEN, P.J., DELANY, A.C., GREENBERG, J., HAAGENSON, P., HEIDT, L., LUEB, R., POLLOCK, W., SEILER, W., WARTBURG, A. \& ZIMMERMAN, P. - 1985 - Tropospheric chemical composition measurements in Brazil during the dry season. J. Atmosph. Chem, 2: 233-256.

DELANY, A.C., HAAGENSEN, P., WALTERS, S, WARTBURG, A.F. \& CRUTZEN, P.J. - 1985 - Photochemically produced ozone in the tropical emission from large-scale tropical fires. J. Geophys. Res., 90: 24252429.

FERNANDES, A.C. - 1988 - A utilização da queimada na colheita da cana-de-açúcar. COPERSUCAR, Såo Paulo, CTAG-1, 17 pp.

FISHMAN, J. - 1985 - Ozone in the troposphere. In Ozone in the free atmosphere (R.C. Whitten \& S.S. Prasad, eds.), Van Nostrand Reinhold, 161-194.

FOSTER, D.H., INKERMAN, P.A. \& MCNEIL, K.E. 1980 - Studies on cane deterioration in Australia. In Proc. of the 17th Int. Society of Sugar Cana Technology, 22042220 .
GREENBERG, J,P., ZIMMERNAN, P, HEIDT, L. \& POLLOCK, W. - 1984 - Hydrocarbons and carbon monoxide emissions from biomass burning in Brazil. $\mathrm{J}$. Geophys. Res., 89: 1350-1354.

IBGE (Fundação Instituto Brasileiro de Geografia e Estatística) - 1975/1989 - Levantamento sistemático da produção agrícola: pesquisa mensal de previsăo de acompanhamento das safras agrícolas no ano civil. Rio de Janeiro,

KIRCHHOFF, V.W.J.H. - 1990 - Biomass burning in the Brazilian Amazon region. Biomass Burning Conference, Williamshurg, VA, 19-23.

KIRCHHOFF, V.W.J.H. - $1988 \mathrm{a}$ - Surface m.one measurements in Amazonia. J. Geophys. Res., 93: 1469-1476.

KIRCHHOFF, V.W.J.H. - 1988b - Variaçöes temporais da concentraçẩo de ozônio de superfície. Rev. Bras. Geof., 1 : 3-8.

KIRCHHOFr, V.W.J,H, \& MARINHO, E.V.A. - 1988 - A concentraçấo de monóxido de carhono $(\mathrm{CO})$ no ar como parâmetro de pureza. Rev. Bras. Geof., 1: 9-16.

KIRCHHOFF, V.W.J.H. \& MARINIIO, E.V.A. - 1989 - A survey of continental concentrations of atmospheric $\mathrm{CO}$ in the Southern Hemisphere. Atmospheric Environment, 23: 461-466.

KIRCHHOFF, V.W.J.I., MARINIIO, E,V.A., DIAS, P.L.S., CALHEIROS, R., ANDRE, R. \& VOLPE, C. $1989 \mathrm{a}-\mathrm{O}_{3}$ and $\mathrm{CO}$ from burning sugar cane. Nature, 339: 264.

KIRCHHOFF, V.W.J.11., SETZER, A.W. \& PEREIRA, M.C. - 1989b - Biomass burning in Amazônia: seasonal effects on atmospheric $\mathrm{O}_{1}$ and $\mathrm{CO}$, Geophys. Res. Letl., 16: 469-472.

KIRCHHOFF, V.W.J.H., MARINITO, E.V.A., DIAS, P.L.S., PEREIRA, E.B., CALHEIROS, R. \& ANDRÉ, R. - 1991 - Enhancements of $C O$ and $O_{3}$ from burning in sugar cane fields. J. Atmosph. Chen., [2: 87-102. 
LOGAN, J.A. - 1985 - Tropospheric ozone: seasonal behavior, trends and anthropogenic influence. J. Geophys. Res., 90: 10463-10482.

MENDONÇA, F,J., BATISTA, G.T. \& TARDIN, A.T, 1989 - Projeto CANASATE: sensoriamento remoto aplicado ao levantamento da cultura canavieira. INPE-4902PRE/1503, 17 pp.

RAISON, R.J., WOODS, P.V., JAKOBSEN, B.F. \& BARY, G.A.V. - 1986 - Soil temperatures during and following low-intensity prescribed burning in a Eucalyptus pauciflora forest. Aust. J. Soil Res., 24: 33-47.
SEILER, W. \& CRUTZEN, P.J. - 1980 - Estimates of gross and net fluxes of carbon between the biosphere and the atmosphere from biomass burning. Climatic Change, 2: 207-247.

SILLMANN, S., LOGAN, J.A. \& WOFSY, S.C. - 1989 The sensitivity of ozone to nitrogen oxides and hidrocarbons in region ozone episodes. Aceito para publicaçāo no J, Geophys. Res.

Versắo recebida em: 09/11/90 Versāo revista e aceita em: 06/05/91 Editor Associado: M.A.F. Silva Dias 